\title{
Yellow cedar response to climatic shifts at Cedar Lake: Juneau, Alaska
}

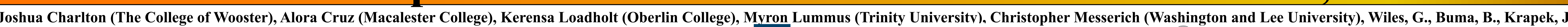

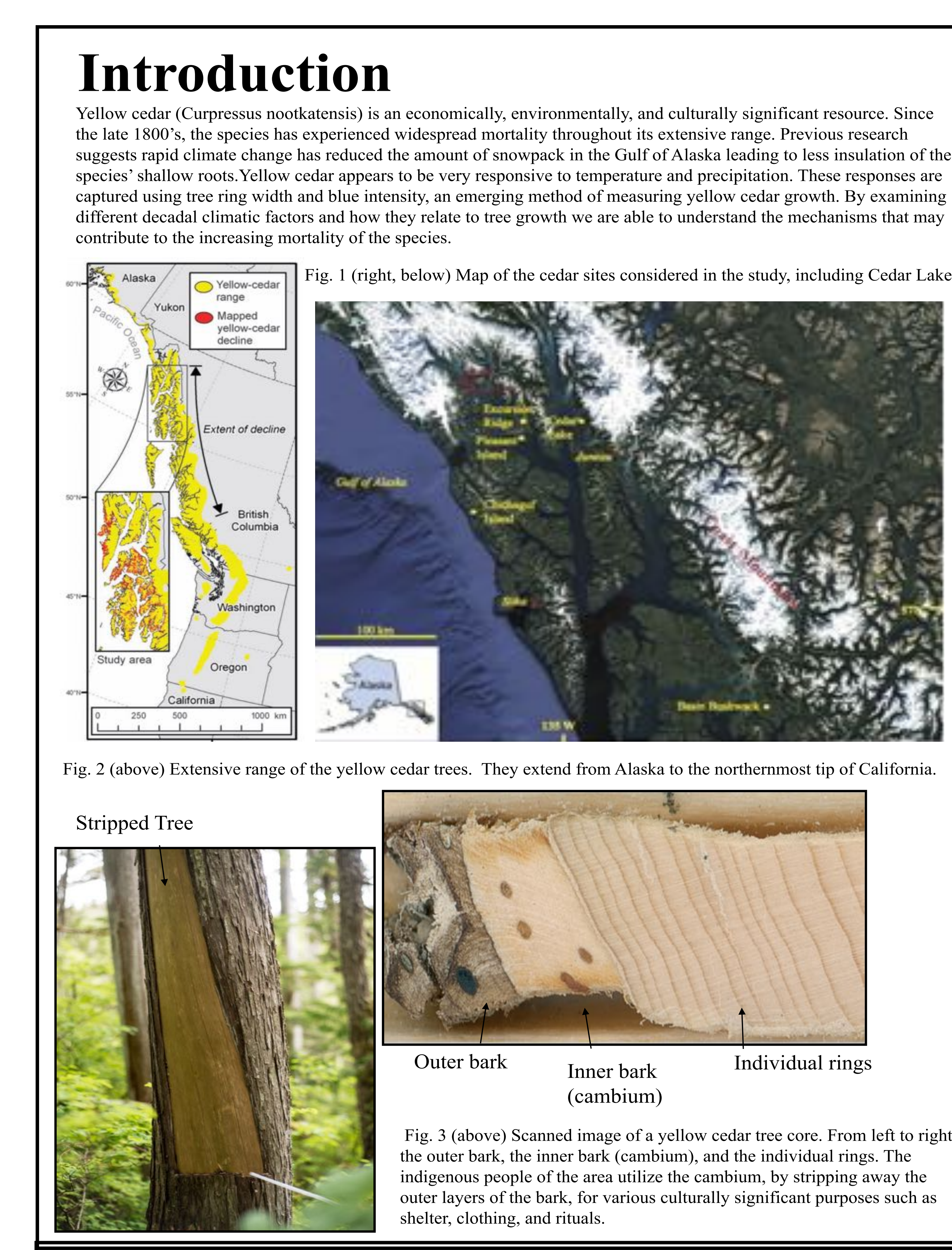

Methods

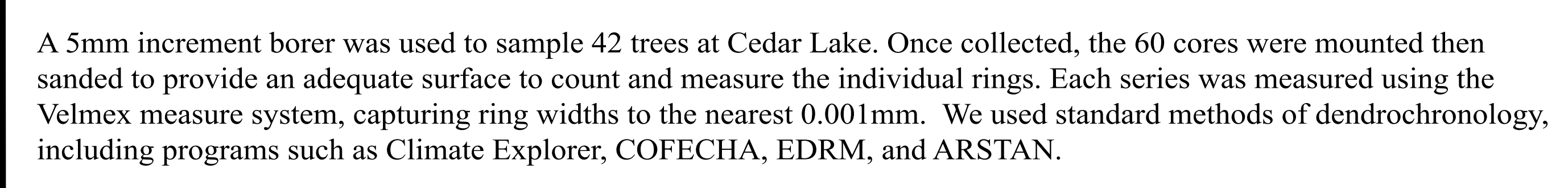

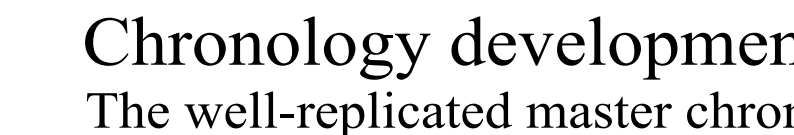

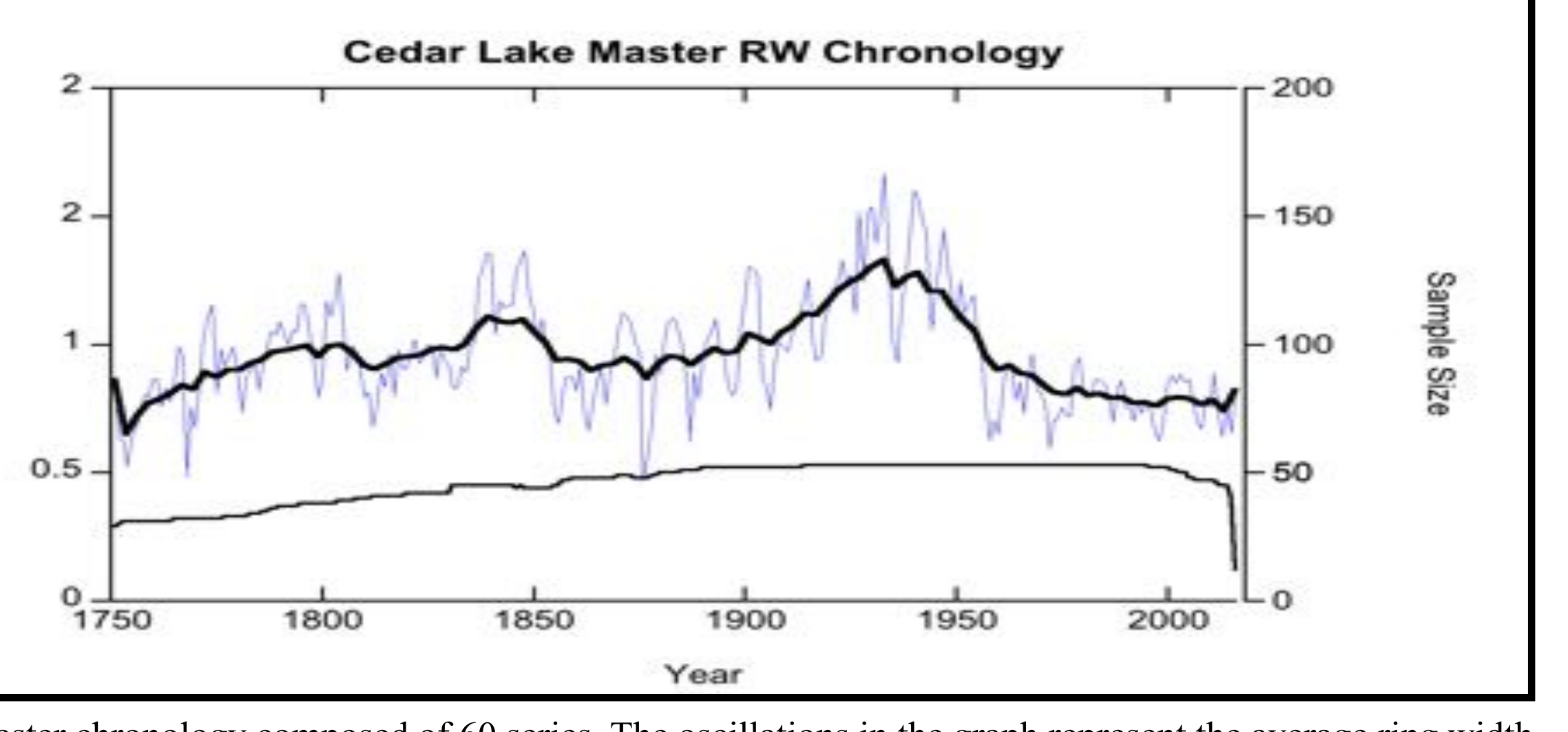

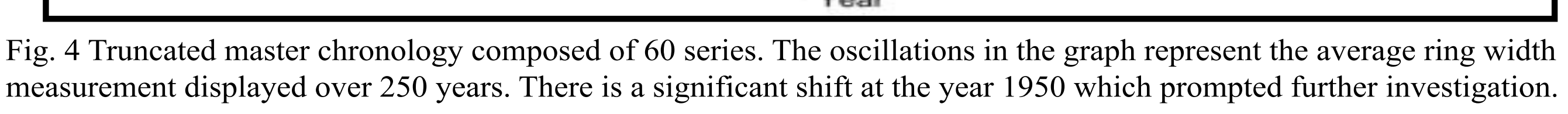

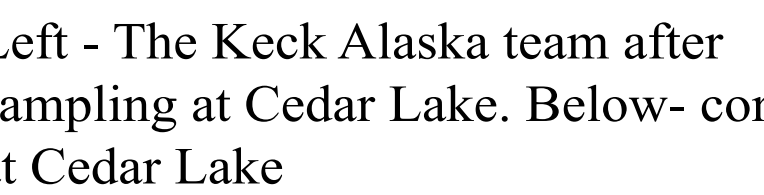

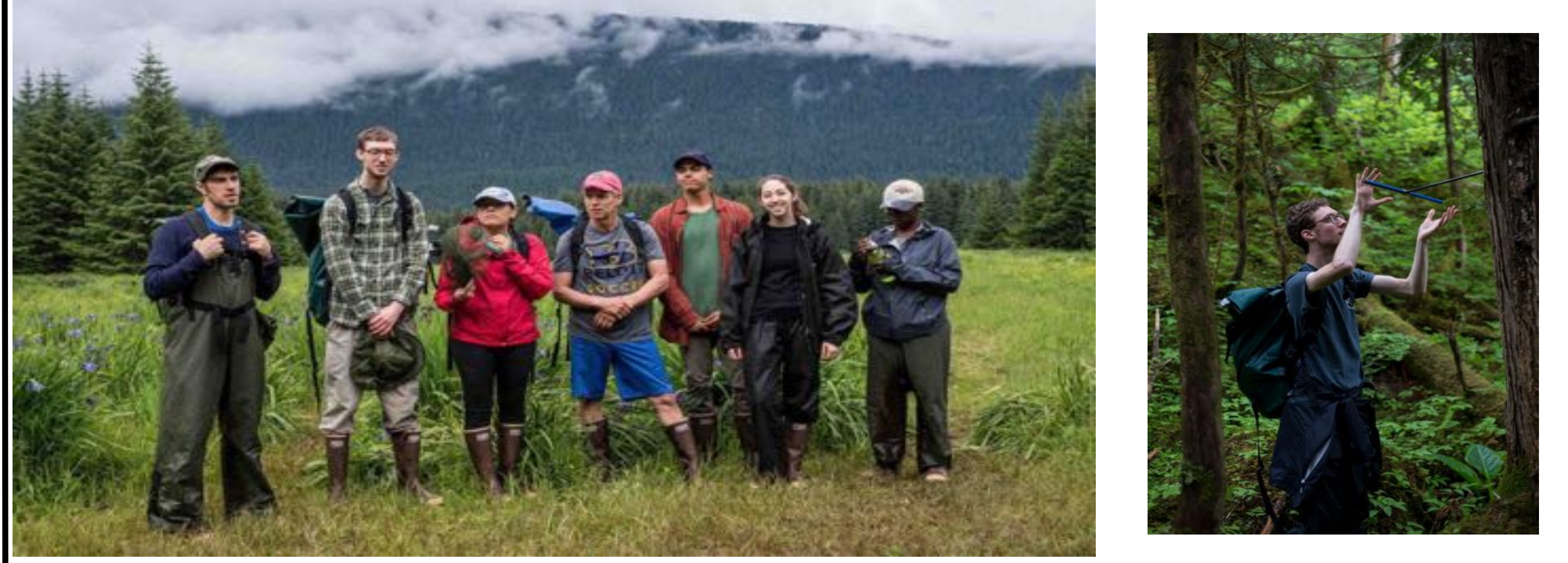

WOOSTER

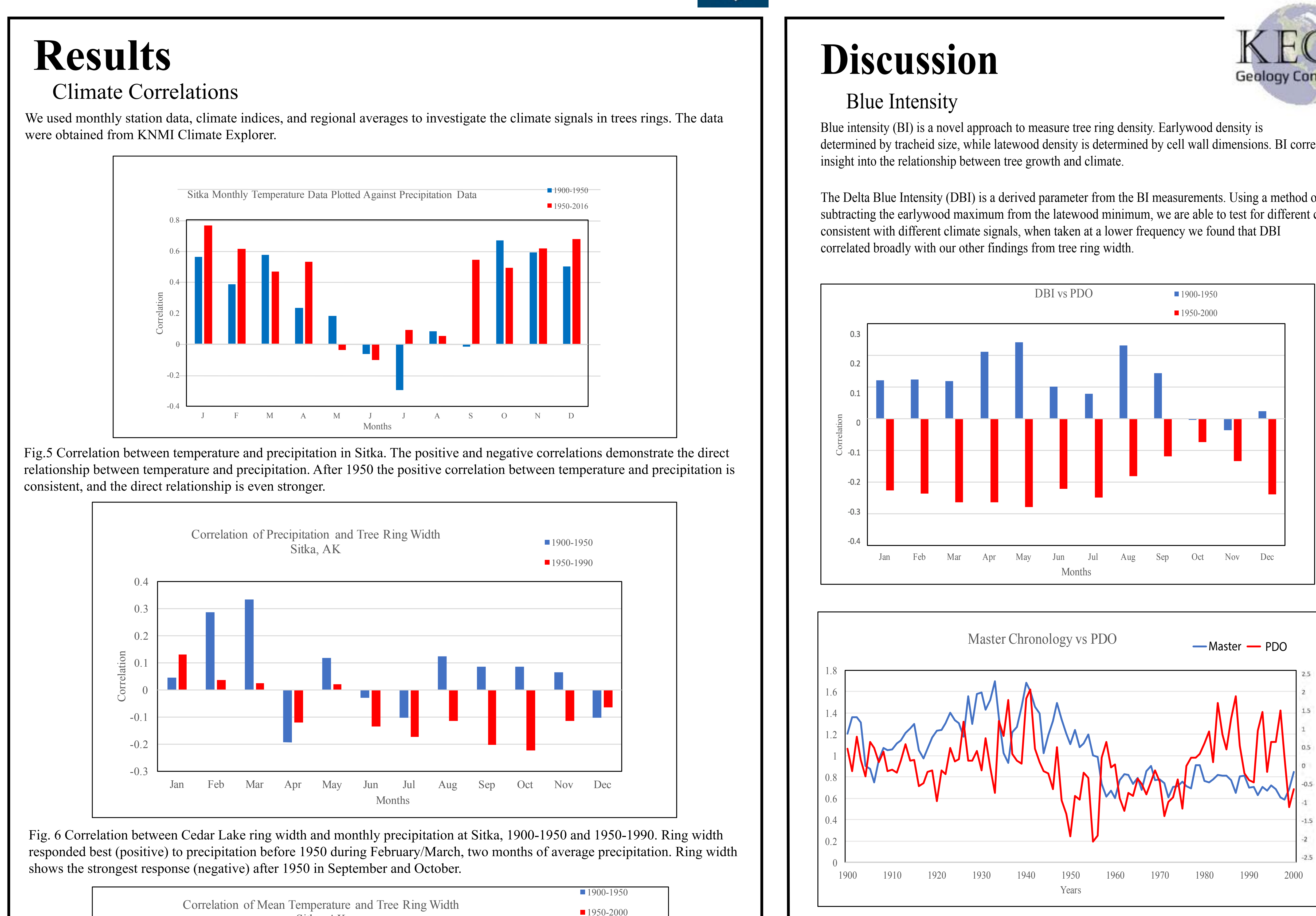

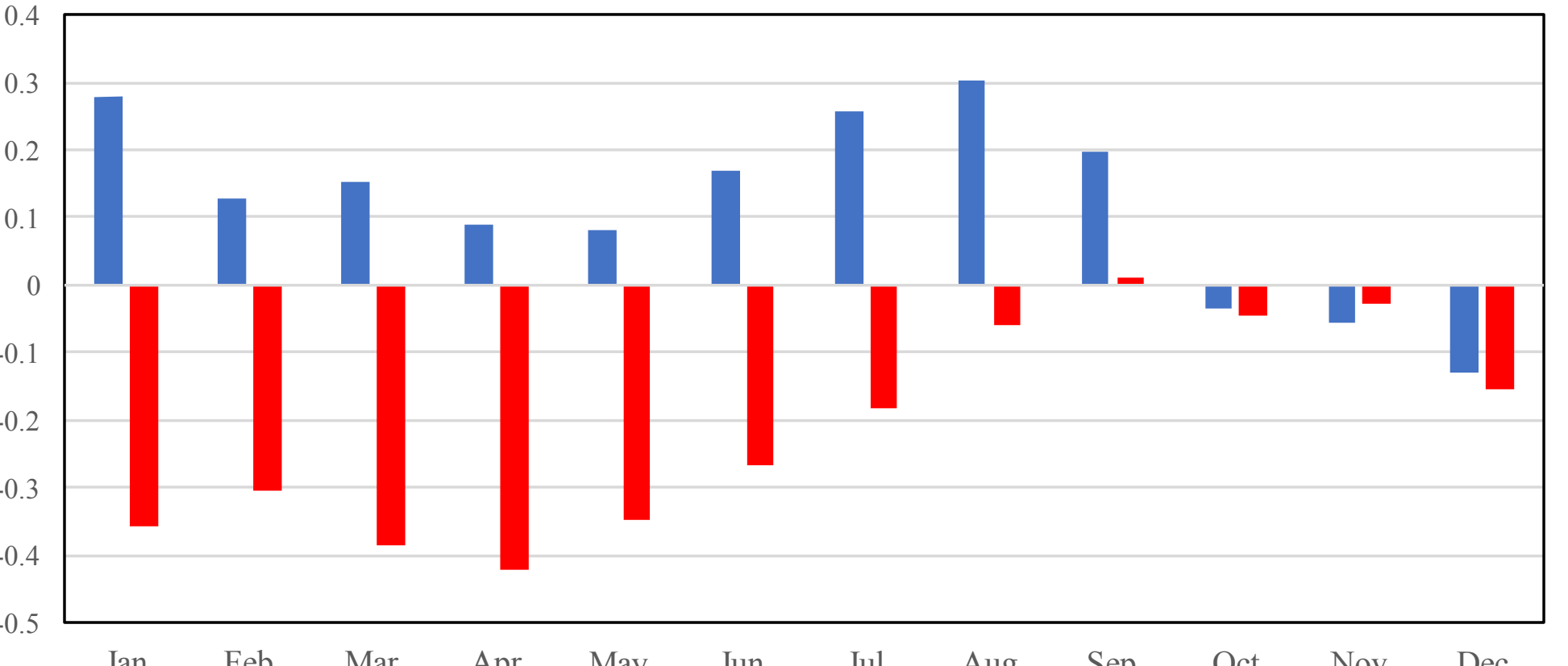

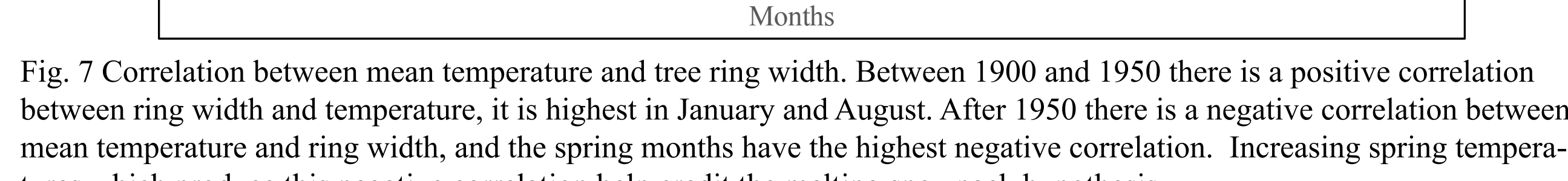

Pacific Decadal Oscillation

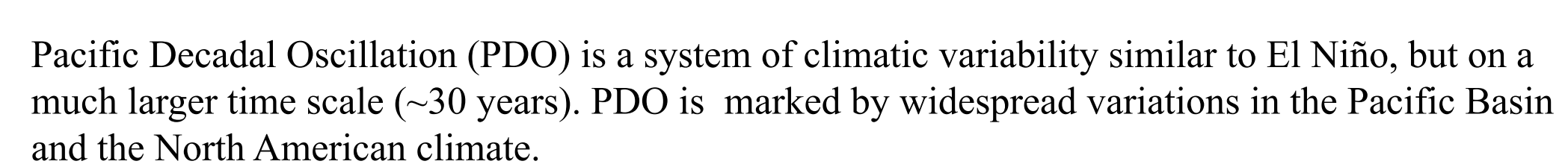

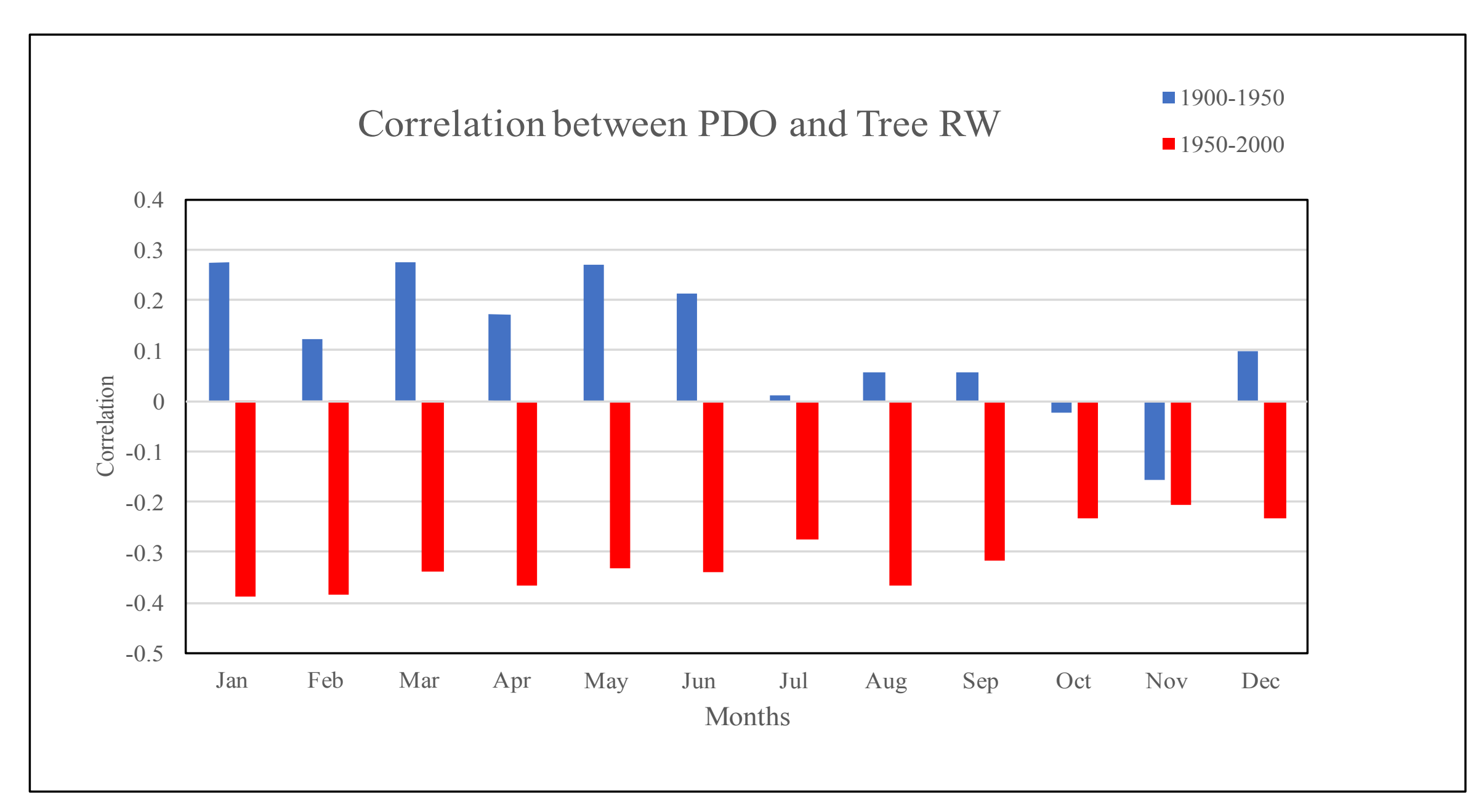

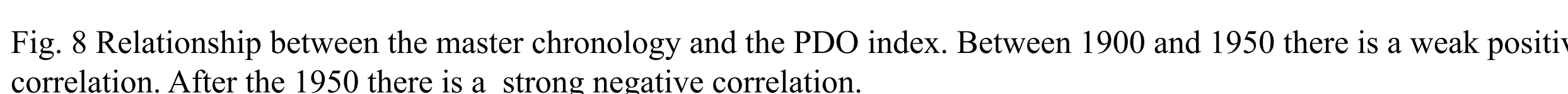

TINITY

W\&L

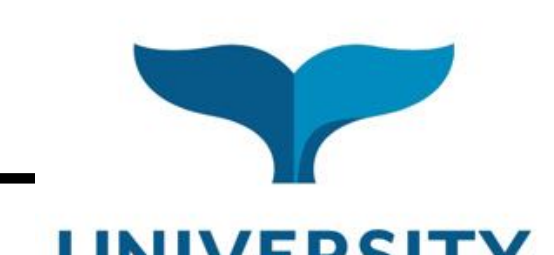
UNIVERSITY Of ALASKA

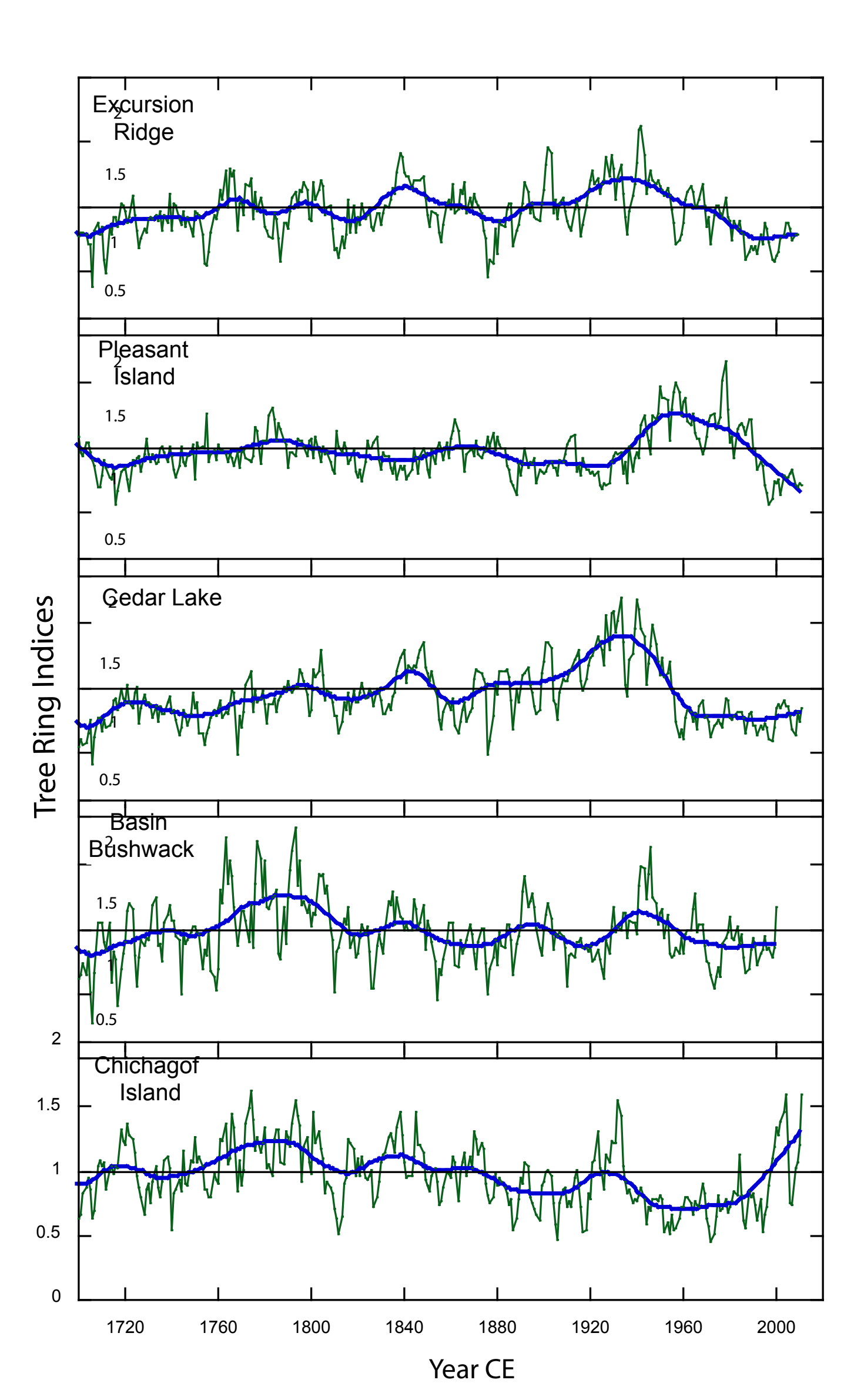

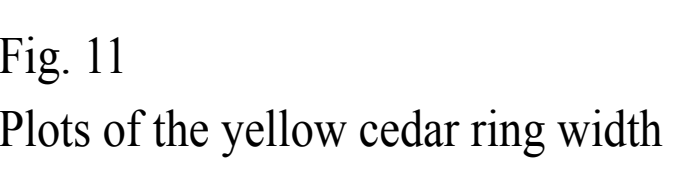

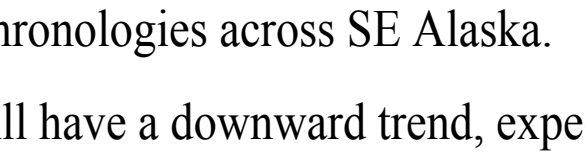

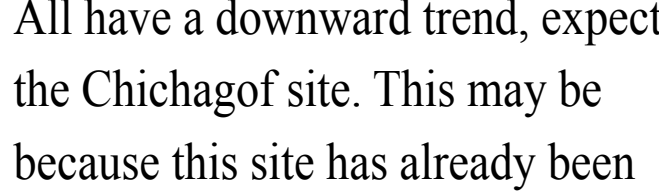

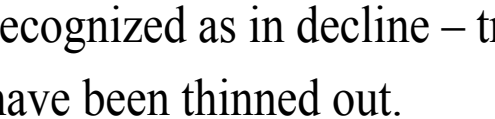

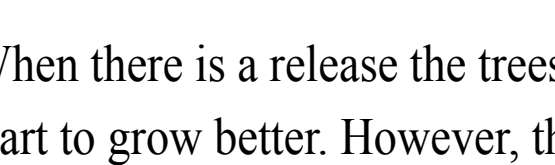

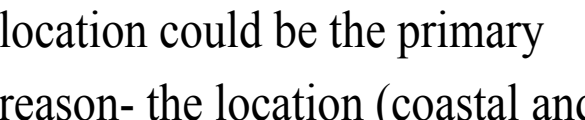

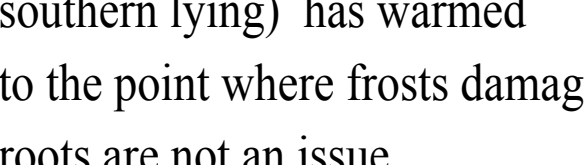

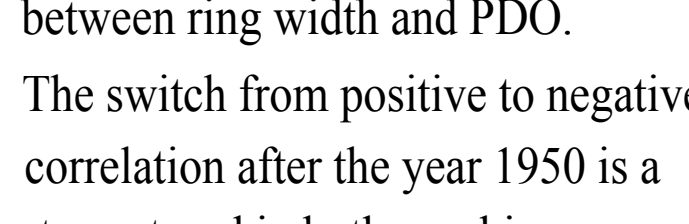

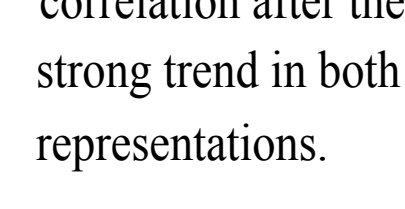

党:

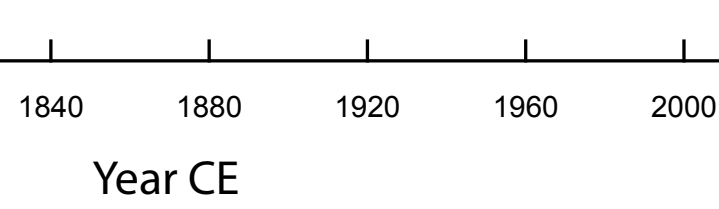

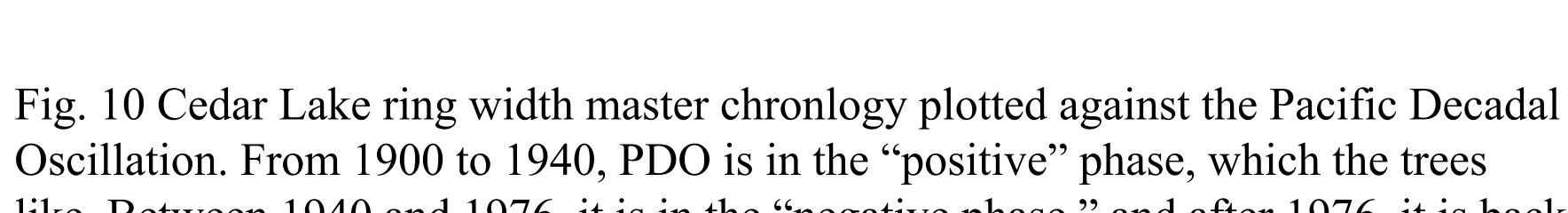

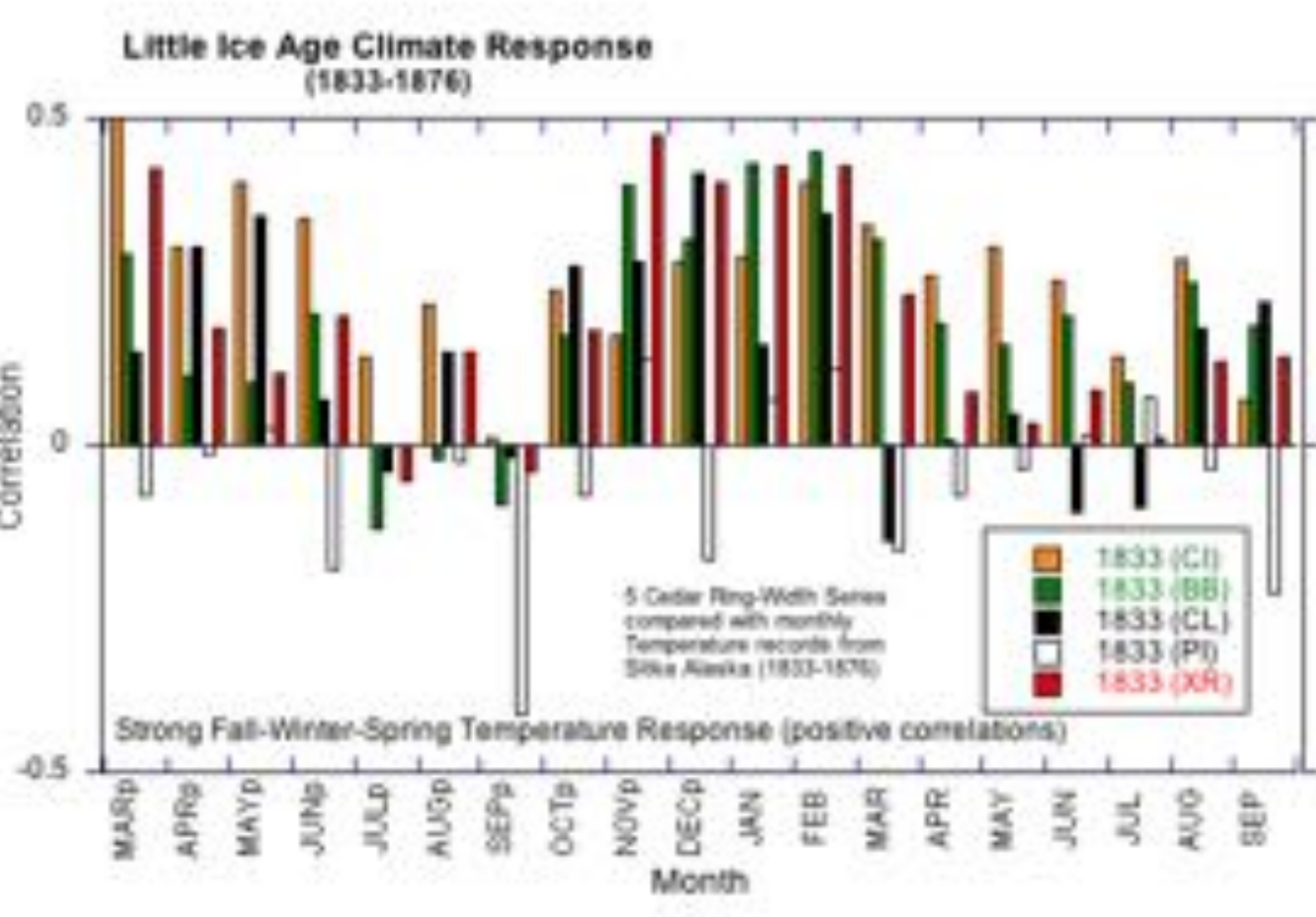

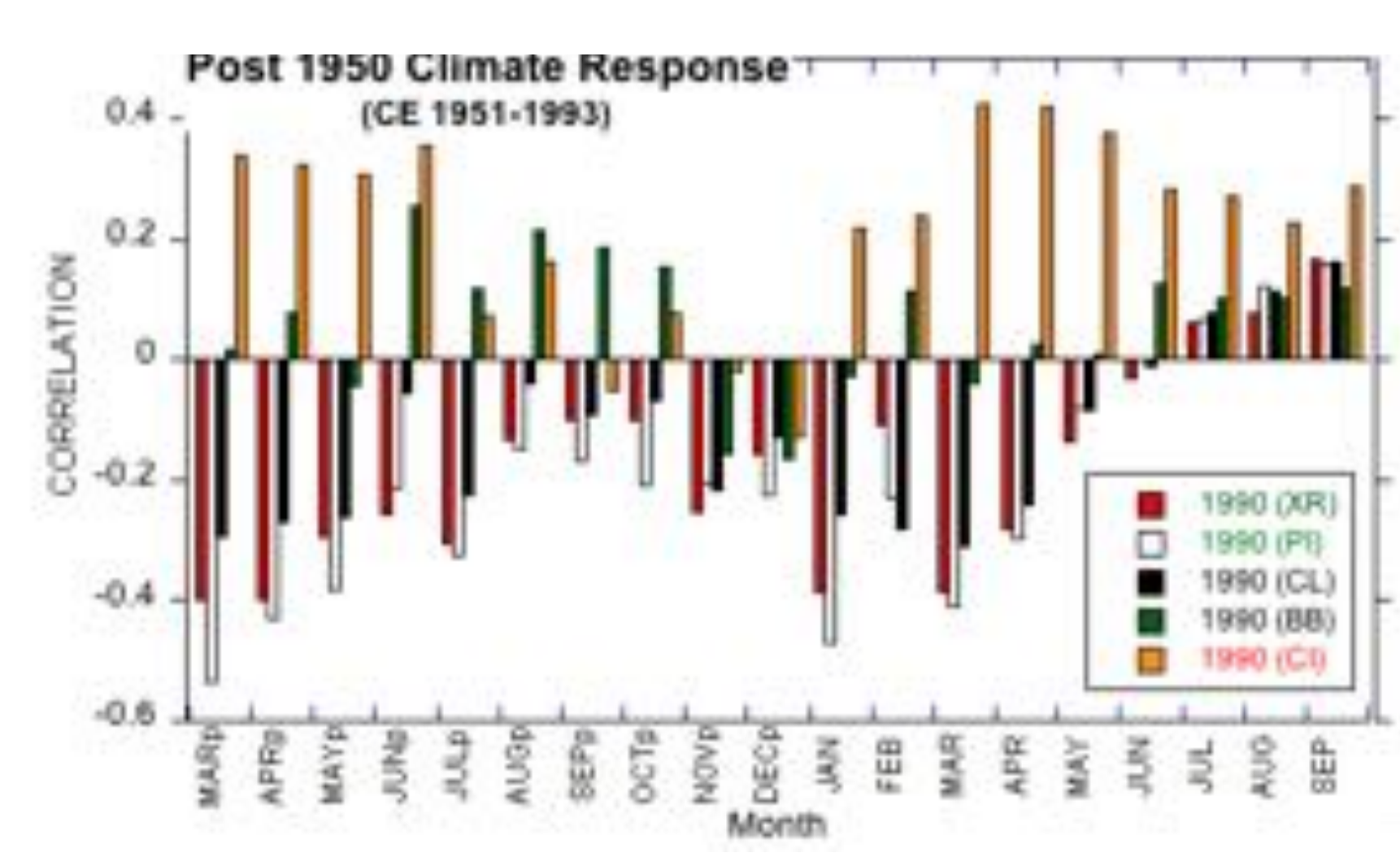

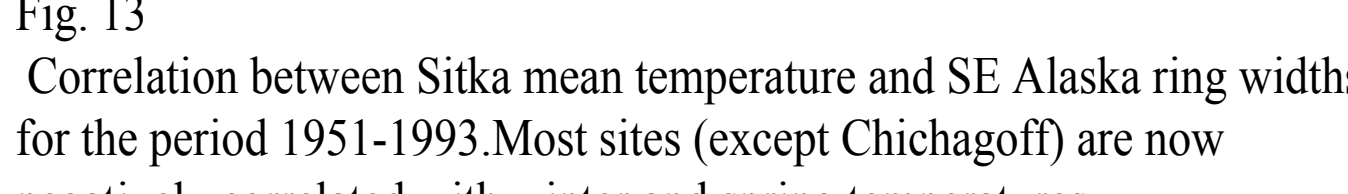

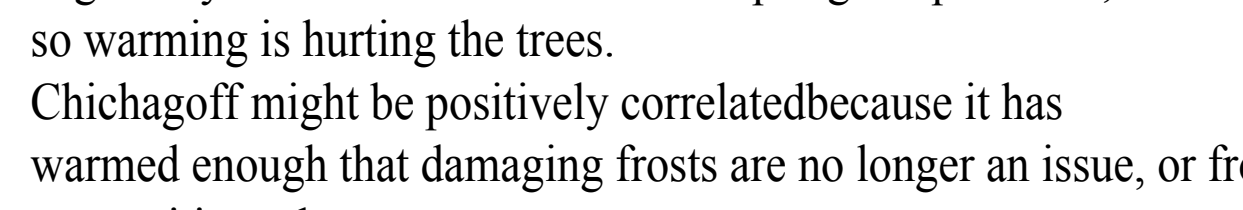

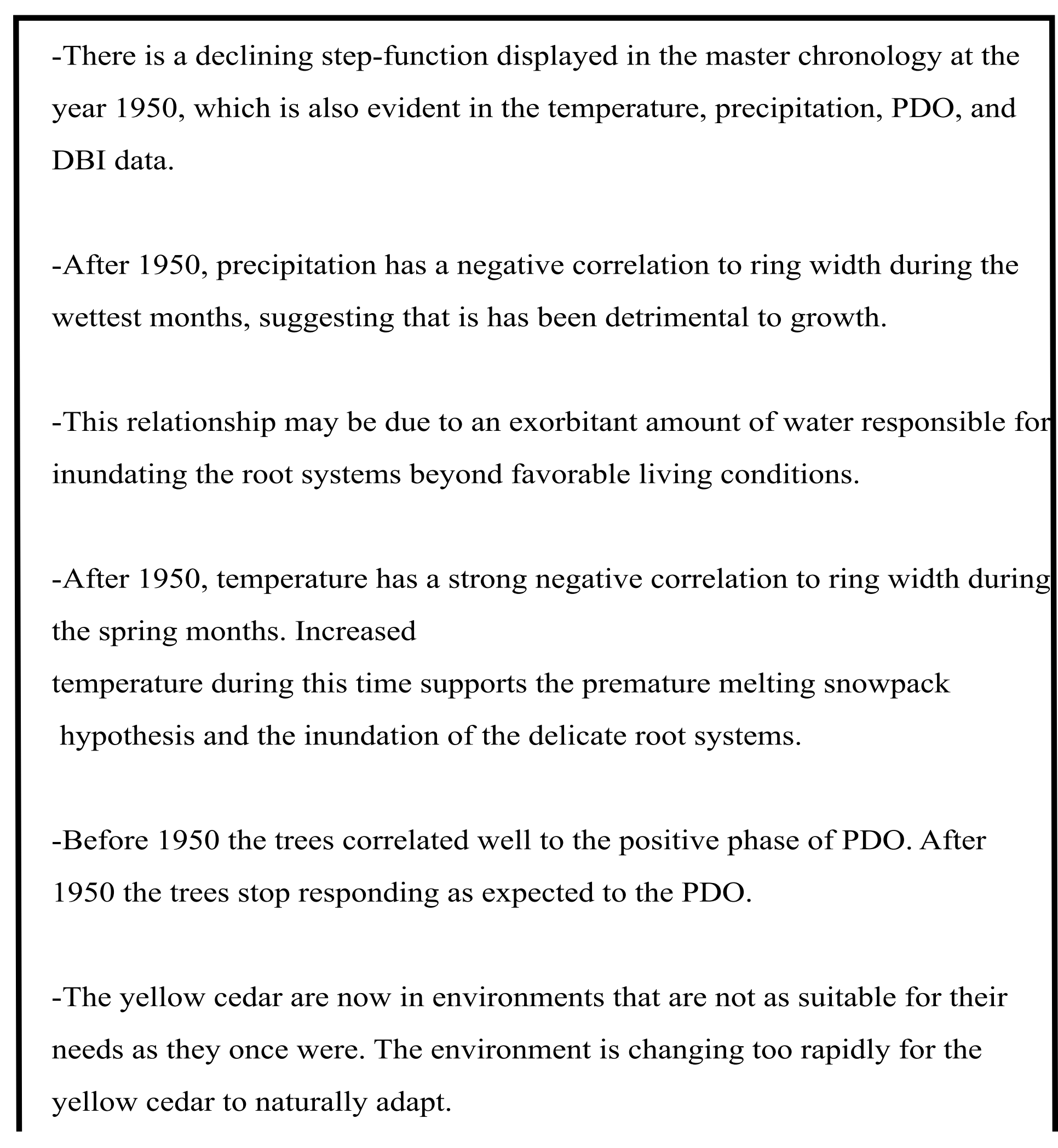

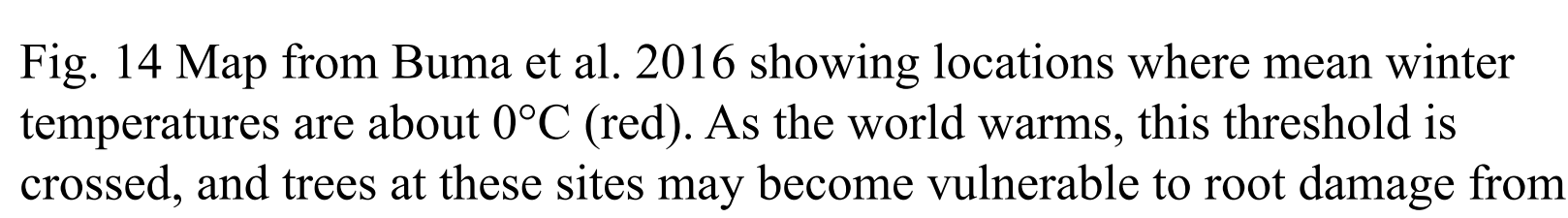

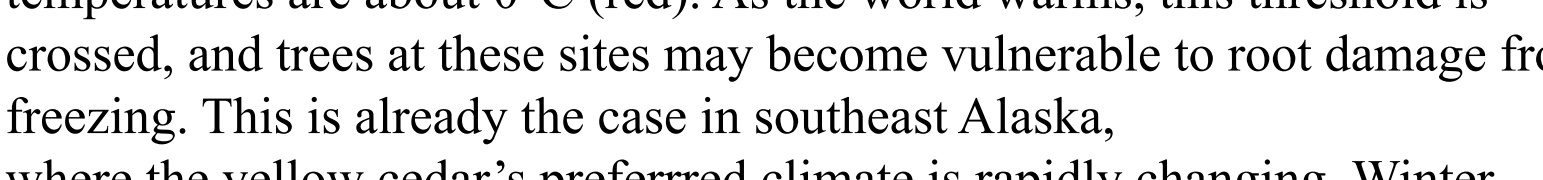

KECK Learning Science

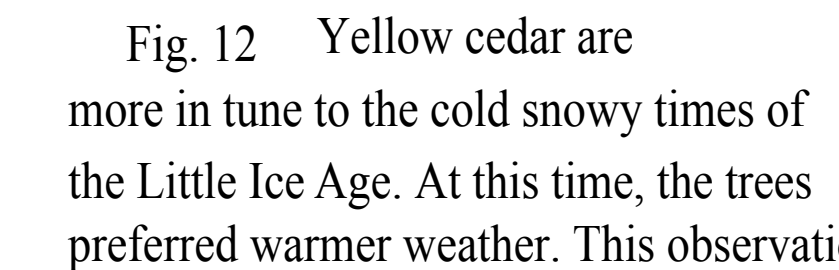

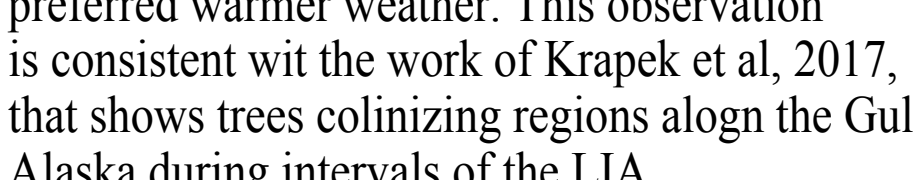

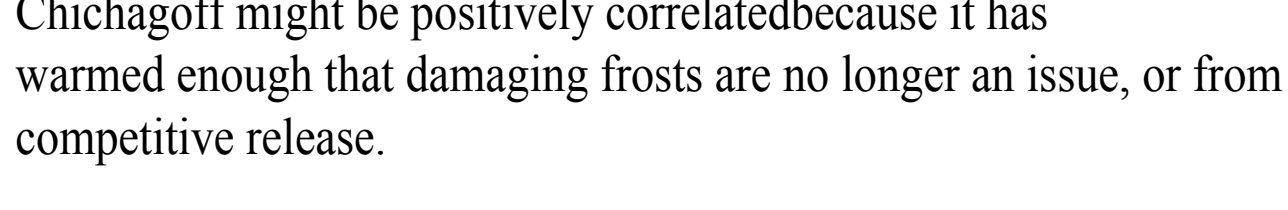

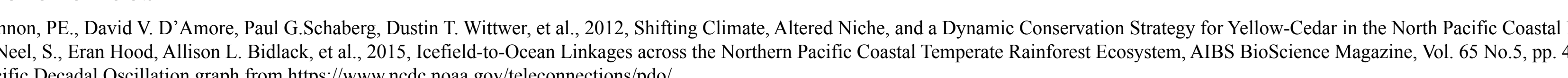

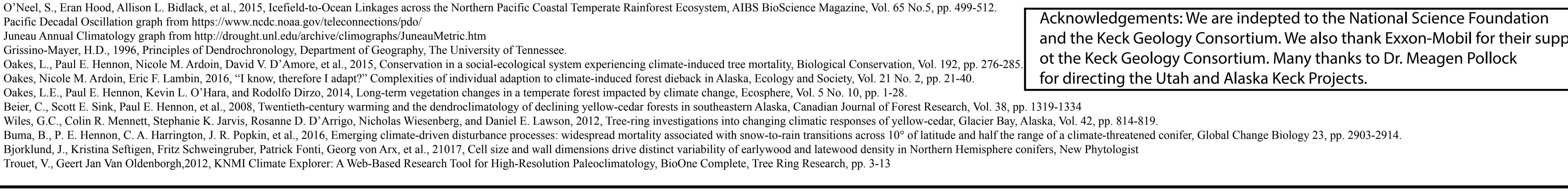

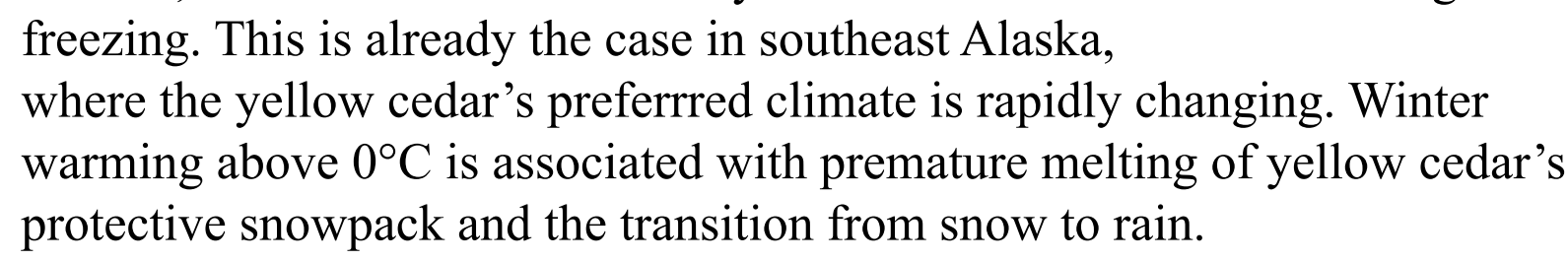

